\title{
Redd1 protects against post-infarction cardiac dysfunction by targeting apoptosis and autophagy
}

\author{
PIANPIAN HUANG ${ }^{1}$, JUN FU $^{2}$, LONG CHEN ${ }^{3}$, CHENHUI JU $^{3}$, KEFEI WU ${ }^{1}$, HONGXIA LIU ${ }^{1}$, \\ YUN LIU $^{1}$, BENMING QI $^{4}$, BENLING QI ${ }^{1}$ and LIHUA LIU ${ }^{1}$ \\ ${ }^{1}$ Department of Geriatrics, Union Hospital, Tongji Medical College, Huazhong University of Science and Technology; \\ ${ }^{2}$ Department of Radiology, Wuhan No. 1 Hospital, Tongji Medical College, Huazhong University of Science \\ and Technology; ${ }^{3}$ Clinical Center for Human Genomic Research, Union Hospital, Tongji Medical College, \\ Huazhong University of Science and Technology, Wuhan, Hubei 430022; ${ }^{4}$ Department of Otorhinolaryngology, \\ First People's Hospital of Yunnan Province, Kunming, Yunnan 650000, P.R. China
}

Received May 9, 2019; Accepted September 6, 2019

DOI: $10.3892 /$ ijmm.2019.4366

\begin{abstract}
Post-infarction remodeling is accompanied and influenced by perturbations in the mammalian target of rapamycin (mTOR) signaling. Regulated in development and DNA damage response-1 (Redd1) has been reported to be involved in DNA repair and modulation of mTOR activity. However, little is known about the role of Redd1 in the heart. In the present study the potential contribution of Redd1 overexpression to the chronic phase of heart failure after myocardial infarction (MI) was explored and the mechanisms underlying Redd1 actions were determined. Redd1 was downregulated in the mouse heart subjected to MI surgery. To determine the role of Redd1 in the process of MI, adeno-associated virus 9 mediated overexpression of Redd1 was used to enhance Redd1 content in cardiomyocytes. Redd1 overexpression improved left ventricular dysfunction and reduced the expansion index. Additionally, Redd1 overexpression resulted in suppressed myocardial apoptosis and improved autophagy. Furthermore, the studies revealed that Redd1 overexpression could inhibit the phosphorylation of mTOR and its downstream effectors P70/S6 kinase and 4EBP1. In conclusion, this study demonstrated that Redd1 overexpression protects against the development and persistence of heart failure post MI by reducing apoptosis and enhancing autophagy via the mTOR signaling pathway. The
\end{abstract}

Correspondence to: Dr Benling Qi or Dr Lihua Liu, Department of Geriatrics, Union Hospital, Tongji Medical College, Huazhong University of Science and Technology, 1277 Jiefang Avenue, Wuhan, Hubei 430022, P.R. China

E-mail: qibenlingok_2015@163.com

E-mail: huahuahbhb@163.com

Key words: regulated in development and DNA damage response-1, myocardial infarction, apoptosis, autophagy, mammalian target of rapamycin present study clearly demonstrated that Redd1 is a therapeutic target in the development of heart failure after MI.

\section{Introduction}

Myocardial infarction (MI) constitutes one of the most serious cardiac events with high morbidity and mortality worldwide $(1,2)$. Myocardial remodeling occurs after MI as a compensatory mechanism to decrease wall stress which may lead to inevitable cardiac dilatation, followed by heart failure (3). At present, pharmacological intervention remains the most effective treatment for preventing post-infarction cardiac remodeling and dysfunction (4). The one year mortality rate of patients hospitalized for heart failure after MI was as high as $43.2 \%$ (5). Therefore, it has been crucial to exploit effective intervention targets for attenuating cardiac remodeling and dysfunction post MI, thereby preventing the development of heart failure in post-infarction patients (6).

Apoptosis and autophagy are reported to participate in physiological processes that occur constitutively in the myocardium $(7,8)$. The roles of apoptosis and autophagy in ischemic myocardial injury have been extensively demonstrated in ischemic induced myocardial injury. Increasing evidence suggests that apoptosis and autophagy disruption results in the development of severe left ventricular dysfunction $(9,10)$. As a result, developing a strategy aimed at regulating apoptosis and autophagy is necessary to protect against post-MI cardiac dysfunction. Therefore, the accurate molecular mechanisms that regulate apoptotic and autophagic responses are pivotal for preventing the development of heart failure post MI.

The mammalian target of rapamycin (mTOR) is a highly conserved serine/threonine kinase, belonging to the phosphoinositide kinase-related kinase family (11). mTOR has been reported to activated via the protein kinase B/phosphoinositide 3 kinase pathway (12). This signaling mechanism is centrally involved in physiological hypertrophy but also takes part in pathological remodeling of the heart (12). It is well established that mTOR plays an important role in regulating cellular physiology, metabolism and stress responses (11). 
Previous studies have confirmed that mTOR can concurrently modulate apoptosis and autophagy related pathogenesis in numerous heart diseases (13-15). Furthermore, inhibiting mTOR induced apoptosis and autophagy may exert a protective influence against MI injury $(16,17)$. The exact mechanisms explaining how this signaling pathway regulates apoptosis and autophagy during MI remain to be clarified.

Regulated in development and DNA damage response-1 (Redd1), located on chromosome 10 (10q22.1), is a 232 amino acids protein which is transcriptionally induced by DNA damage in various types of cells $(18,19)$. Redd1 plays a vital role in biological, physiological functions and cellular functions, such as cell growth, inflammation and autophagy (20-22). Despite its relationship with mTOR and extensive research in multiple diseases, such as neurodegenerative disorders (23) and cancer (24), little is known about the role of Redd1 in the heart. Few previous studies have evaluated the hypothesis that Redd1 may have relevance to cardiac physiopathology. Studies have shown that Redd1 inhibition protected cardiomyocytes from ischemia-reperfusion (I/R) injury (25) or methamphetamine-induced myocardial damage (26). Paradoxically, Liu et al (27) demonstrated that Redd1 attenuated cardiac hypertrophy induced by phenylephrine via enhancing autophagy. These observations imply that Redd1 is possibly associated with cardiac dysfunction. However, there was no study on whether Redd1 could ameliorate the prognosis of cardiac dysfunction post MI. At present, the role of Redd1 in the heart remains unknown. Nonetheless, extrapolating experimental data from other cell types, Redd1 appears to play a pivotal role in inhibiting mTOR activation (28-30).

In this context, the present study aimed to explore the potential contribution of Redd 1 during the development of heart failure after MI. The study presented here demonstrates the critical role of Redd1 overexpression in cardiomyocytes during the chronic phases of MI. A single intravenous injection of an adeno-associated virus 9 (AAV9) vector expressing Redd1 reduced left ventricular dysfunction. In addition, Redd1 improved cardiac function after myocardial infarction through apoptosis inhibition and autophagy enhancement mediated by mTOR inactivation. The results of the present study suggest the critical importance of Redd1 in the development of heart failure post MI.

\section{Materials and methods}

Animals. A total of 30 C57BL/6 male mice weighing 14-16 g (4-5 weeks) were purchased from the Beijing HFK Bioscience Co., Ltd. Mice were kept in cages at $22 \pm 2^{\circ} \mathrm{C}$ with $40 \pm 5 \%$ humidity under a $12 \mathrm{~h}$ light/dark cycle in the Tongji Medical School Experimental Animal Center, and fed a chow diet and water. Animal experiments were carried out in accordance with the Guide for the Care and Use of Laboratory Animals published by the National Institute of Health and were approved by the Institutional Animal Care and Use Committee at Tongji Medical College, Huazhong University of Science and Technology.

Injection of AAV9 vectors. The AAV9 vectors carrying enhanced green fluorescent protein (AAV9-GFP) or mouse Redd1 (AAV9-Redd1) were purchased from Weizhen
Biotechnology Company. The sequence of the Redd1 vector was consistent with the coding sequence of mouse Redd1, shown as follows, ATGCCTAGCCTCTGGGATCGTTTC TCGTCCTCCTCTTCCTCTTCGTCCTCGTCTCGAACTC CGGCCGCTGATCGGCCGCCGCGCTCCGCCTGGGGGT CTGCAGCCAGAGAAGAGGGCCTTGACCGCTGCGCGA GCCTGGAGAGCTCGGACTGCGAGTCCCTGGACAGCA GCAACAGTGGCTTCGGGCCGGAGGAAGACTCCTCAT ACCTGGATGGGGTGTCCCTGCCCGACTTTGAGCTGC TCAGTGACCCCGAGGATGAGCACCTGTGTGCCAACC TGATGCAGCTGCTGCAGGAGAGCCTGTCCCAGGCGC GATTGGGCTCGCGGCGCCCTGCGCGTTTGCTCATGC CGAGCCAGCTGGTGAGCCAGGTGGGCAAGGAACTCC TGCGCCTGGCATACAGTGAGCCGTGCGGCCTGCGGG GGGCACTGCTGGACGTGTGTGTGGAGCAAGGCAAG AGCTGCCATAGCGTGGCTCAGCTGGCCCTCGACCCC AGCCTGGTGCCCACCTTTCAGTTGACCCTGGTGCTG CGTCTGGACTCTCGCCTCTGGCCCAAGATCCAGGGG CTGTTAAGTTCTGCCAACTCTTCCTTGGTCCCTGGTT ACAGCCAGTCCCTGACGCTAAGTACCGGCTTCAGAG TCATCAAGAAGAAACTCTACAGCTCCGAGCAGCTGC TCATTGAAGAGTGTTGA. Mice were injected with viral solution $\left(2.8 \times 10^{11}\right.$ vector genomes per mouse $)$ via the tail vein 4 weeks before MI surgery (31).

MI surgery and experimental groups. MI was induced by permanent ligation of the left-anterior descending coronary artery (LAD) as previous reported (32). Briefly, mice were anesthetized with $3 \%$ pentobarbital sodium $(50 \mathrm{mg} / \mathrm{kg})$ by intraperitoneal injection. Mice were mechanically ventilated. A thoracotomy was conducted between the left third and fourth ribs. The thymus was retracted upwards and the auricular appendix was exposed. The LAD was ligated by a 6-0 silk suture. The sham group mice underwent the same process except for ligating the LAD. Mice were randomly divided into four groups: Sham with AAV9-GFP (Sham+GFP; n=6), Sham with AAV9-Redd1 (Sham+Redd1; n=6), MI with AAV9-GFP (MI+GFP; $n=8$ ) and MI with AAV9-Redd1 (MI+Redd1; $n=8$ ). Mice were treated with AAV9-Redd1 or AAV9-GFP for 4 weeks before MI or sham operation. Mice were sacrificed at 4 weeks post MI or sham surgery.

Echocardiography. A total of 4 weeks following MI, mice were anesthetized with $1.5 \%$ isoflurane via inhalation (33). The depth of anesthesia was determined by immobility and assessing the absence of the withdrawal reflex of the right paw. Subsequently, cardiac function was measured by transthoracic echocardiography with a Vevo 2100 high-resolution micro imaging system (VisualSonics, Inc.). The echocardiography images were acquired from the long axes and the short axis. The following parameters were measured in M-mode: Left ventricular end-diastolic diameter (LVEDd) and left ventricular end-systolic diameter (LVESd). The percentage of left ventricular fractional shortening (LVFS, \%) and left ventricular ejection fraction (LVEF, \%) were automatically calculated. The parameters were acquired and averaged from six cardiac cycles.

Masson's trichrome staining and picrosirius red staining. Heart tissues were fixed with $4 \%$ paraformaldehyde for $24 \mathrm{~h}$ at room temperature, subsequently paraffin embedded and 
sectioned into $5 \mu \mathrm{m}$ thick slices. Masson's trichrome and picrosirius red staining were carried out in accordance with standard procedures (34). The stained sections were used to estimate scar thickness, infarct size and expansion index as previously stated $(35,36)$. Picrosirius red staining was applied to calculate the percentage of collagen content in the border zone of the infarcted heart. The images were acquired at x200 magnification in the border zone of the infarct area, using a light microscope (Olympus Corporation), and analyzed with Image-Pro Plus software 6.0 (Media Cybernetics, Inc.).

Immunofluorescent assay. Paraffin slides were deparaffinized for immunofluorescent staining. All sections were incubated with primary antibodies for Redd1 (1:50; cat. no. ab106356; Abcam) and LC3B (1:50; cat. no. Arg55799; Arigo Biolaboratories, Corps.) at $4^{\circ} \mathrm{C}$ overnight. Fluorescein tetramethylrhodamine-conjugated secondary antibody affinipure goat anti-rabbit Immunoglobulin $\mathrm{G}(\mathrm{H}+\mathrm{L} ; 1: 50$; cat no. 111-025-144; Jackson ImmunoResearch Europe, Ltd.,) was incubated for $1 \mathrm{~h}$ at room temperature. Then, all slides were stained with 300 nM DAPI (D1306, Invitrogen; Thermo Fisher Scientific, Inc.) for $5 \mathrm{~min}$ at room temperature. In each sample, three random fields were observed by fluorescence microscopy at $\mathrm{x} 200$ magnification. The relative fluorescence intensity was estimated with ImageJ software (version 1.51, National Institutes of Health).

Terminal deoxynucleotidyl-transferase mediated dUTP nick-end labeling (TUNEL) assay. The cardiac cell apoptosis level in the infarct zone of the heart was determined by TUNEL staining. In accordance with the manufacturer's protocol supplied by the TUNEL detection kit (Roche Diagnostics), the heart sections were treated with TUNEL reagent for $1 \mathrm{~h}$ at $37^{\circ} \mathrm{C}$. Subsequent to washing with twice PBS, the sections were counterstained with 300 nM DAPI (D1306, Invitrogen; Thermo Fisher Scientific, Inc.) for $5 \mathrm{~min}$ at room temperature. In each sample, images of three random fields were captured with a 100X lens by fluorescence microscopy. The percentage of positive apoptotic cells was estimated with ImageJ software.

Tissue separation. The atrial tissue was removed and the left ventricle was cut open. The infarct tissue and the border tissue were separated from the heart for western blotting and PCR analysis. As shown in Fig. 1A, the infarcted area was thin and pale, located within the black solid line. The border zone was a transitional pink area, thinner than normal myocardial tissue, located between the black solid line and the black dotted line (37).

Western blotting. The myocardial total protein was extracted using with RIPA lysis buffer (Beyotime Institute of Biotechnology) at $4^{\circ} \mathrm{C}$ for $30 \mathrm{~min}$, then quantified with a bicinchoninic acid kit (Beyotime Institute of Biotechnology). Equal amounts of denatured protein samples $(100 \mu \mathrm{g})$ were separated by $12 \%$ SDS-PAGE and were transferred to nitrocellulose membranes. The nitrocellulose membranes were blocked in $5 \%$ milk diluted with TBS/0.1\% Tween-20 (TBST) for $2 \mathrm{~h}$ at room temperature, following by primary antibody incubation overnight at $4^{\circ} \mathrm{C}$. The primary antibodies were as follows: Anti- $\beta$ tubulin $(1: 1,000$; cat. no. 66240-1-Ig, ProteinTech Group, Inc.); anti-Redd1 (1:1,000; cat. no. ab106356; Abcam);
anti-Bcl2 (1:1,000; cat. no. A11025, Abclonal Biotech Co., Ltd.); anti-Bax (1:1,000; cat. no. A12009; Abclonal Biotech Co., Ltd.); anti-LC3B (1:1,000; cat. no. Arg55799; Arigo Biolaboratories, Corps.); and anti-Beclin1 (1:1,000; cat. no. A7353; Abclonal Biotech Co., Ltd.); anti-total-mTOR (1:1,000; cat. no. A2445; Abclonal Biotech Co., Ltd.); anti-phosphorylated (phospho)-mTOR (1:1,000; cat. no. AP0094; Abclonal Biotech Co., Ltd.), anti-total-P70/S6 kinase [1:1,000; cat. no. 2708t; Cell Signaling Technology, Inc., (CST)]; anti-phospho-P70/S6 kinase (1:1,000; cat. no. 9208t; CST); anti-total-4EBP1 (1:1,000; cat. no. 9644t; CST); anti-phospho-4EBP1 (1:1,000; cat. no. 9451t; CST). The membranes were washed with TBST 3 times, following by incubation with HRP-conjugated secondary antibodies anti-rabbit IgG $(\mathrm{H}+\mathrm{L} ; 1: 2,000$; cat. no. ANT020) and anti-mouse $\operatorname{IgG}(\mathrm{H}+\mathrm{L} ; 1: 2,000$; cat. no. ANT019; both Antgene Biotechnology co., Ltd.) for $2 \mathrm{~h}$ at room temperature. Bands were detected with a chemiluminescence detection System (ECL; Thermo Fisher Scientific, Inc.) and quantified by densitometry using ImageJ software.

Reverse transcription-quantitative polymerase chain reaction $(R T-q P C R)$. Myocardial total RNA was extracted with TRIzol reagent (Invitrogen; Thermo Fisher Scientific, Inc.). Complementary DNA was synthesized using the PrimeScript RT Master Mix kit (Takara Bio, Inc.) and then used for qPCR with a SYBR-Green Master Mixture (Takara Bio, Inc.) on the ABI StepOnePlus RT-PCR system (Applied Biosystems, Thermo Fisher Scientific, Inc.). The reverse transcription conditions were as follows: $37^{\circ} \mathrm{C}$ for $15 \mathrm{~min}$ and $85^{\circ} \mathrm{C}$ for 5 sec. The qPCR cycling conditions were as follows: $95^{\circ} \mathrm{C}$ for $10 \mathrm{~min}$ and 40 cycles of $95^{\circ} \mathrm{C}$ for $15 \mathrm{sec}$ and $60^{\circ} \mathrm{C}$ for $15 \mathrm{sec}$. qPCR was performed with 3 replicates of each sample. The relative expression quantity was analyzed by normalizing to the GAPDH level and calculated with the $2^{-\Delta \Delta \mathrm{Cq}}$ method (38). The primers were as follows: 5'-AGGTCGGTGTGAACG GATTTG-3' and 5'-AGGTCGGTGTGAACGGATTTG-3' for GAPDH, 5'-GCTTCCAGGCCATATTGGAG-3' and 5'-GGG GGCATGACCTCATCTT-3' for natriuretic peptide type A (ANP), 5'-GAGGTCACTCCTATCCTCTGG-3' and 5'-GCC ATTTCCTCCGACTTTTCTC-3' for natriuretic peptide type B (BNP), 5'-ACTGTCAACACTAAGAGGGTCA-3' and 5'-TTGGATGATTTGATCTTCCAGGG-3' for myosin heavy polypeptide 7 ( $\beta$-MHC), 5'-GCTCCTCTTAGGGGCCACT-3' and 5'-CCACGTCTCACCATTGGGG-3' for collagen I, 5'-ACGTAGATGAATTGGGATGCAG-3' and 5'-GGGTTG GGGCAGTCTAGTG-3' for collagen III.

Statistical analysis. Each experiment was repeated $\geq 3$ times. All data were analyzed by Prism 5 (GraphPad Software Inc.) and presented as the mean \pm standard error of the mean. The differences in the data were analyzed. Unpaired, two-tailed Student's t-test was used for two groups. One-way analysis of variance was used for multiple comparisons. Post hoc differences were determined by Newman Keuls test. $\mathrm{P}<0.05$ was considered to indicate a statistically significant difference.

\section{Results}

Reddl is downregulated in the heart during the myocardial infarction process. To investigate whether Redd1 
A
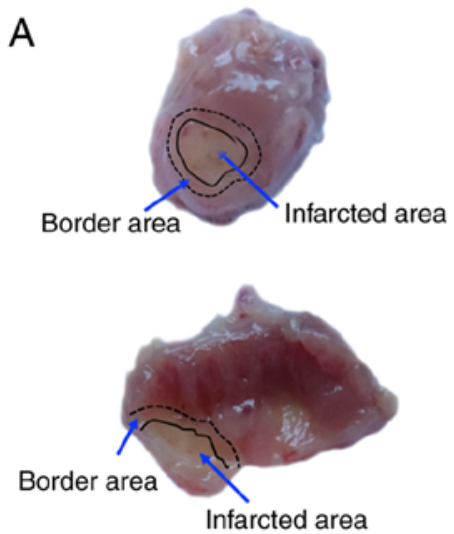

D
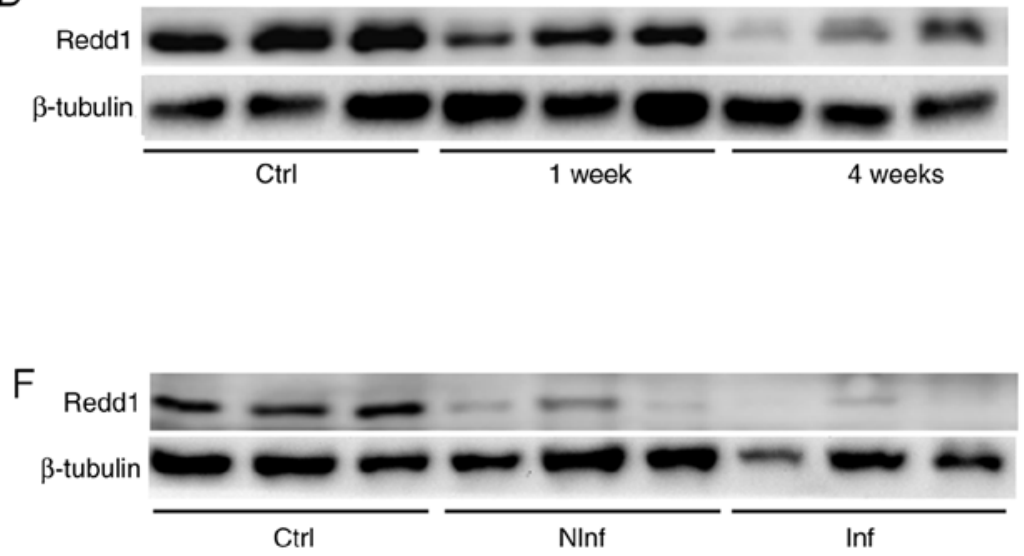

B

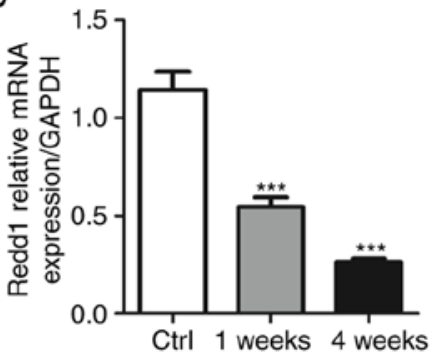

Figure 1. Redd1 is downregulated in the heart during the MI process. (A) Representative images of infarct and border area. Upper: Image in front of the heart Down: Anatomical left ventricle. The black solid line is the boundary of the infarct area; the black dotted line indicates the boundary of the border area. (B) mRNA levels of Redd1 in the heart of sham-operation mice or in infarct region of MI mice at different time points (1 week and 4 weeks) after MI surgery $(\mathrm{n}=6-8)$. (C) mRNA levels of Redd1 in the heart of sham-operation mice or in different regions (border area and infarct area) at 4 weeks post MI surgery $(\mathrm{n}=6-8)$. (D and E) Redd1 protein expression in the heart of sham-operation mice or in the infarct region of MI mice at different time points (1 and 4 weeks) after MI surgery $(\mathrm{n}=6-8)$. ( $\mathrm{F}$ and $\mathrm{G})$ The protein levels of Redd1 in the heart of sham-operation mice or in different regions (border area and infarct area) at 4 weeks post MI surgery $(n=6-8)$. Data presented as mean \pm standard error of the mean. ${ }^{*} \mathrm{P}<0.05,{ }^{* *} \mathrm{P}<0.01$ and ${ }^{* * *} \mathrm{P}<0.001$ vs. the sham group. Redd1, regulated in development and DNA damage response-1; Ctrl, control group; MI, myocardial infarction; Inf, infarction region; Ninf, non-infarction region. is involved in MI, LAD-induced MI models were used (Fig. 1A). Redd1 mRNA and protein levels in the infarct zone declined significantly at different time points $(1$ and 4 weeks) after MI compared with sham-operation animals $(\mathrm{P}<0.001$; Fig. 1B, D and E). Meanwhile, Redd1 mRNA and protein expression declined significantly in different regions (border area and infarct area) at 4 weeks compared with the sham group $(\mathrm{P}<0.05$; Fig. $1 \mathrm{C}, \mathrm{F}$ and $\mathrm{G})$. These data indicate that Redd1 expression in the heart is downregulated during MI, suggesting that Redd 1 may participate in the process of MI.

Reddl overexpression protects against cardiac dysfunction after MI. To investigate the influence of Redd1 on cardiac dysfunction and remodeling post-MI, AAV9-Redd1 or control AAV9-GFP was injected via the tail vein 4 weeks prior to permanent LAD ligation. A total of 8 weeks after injection, AAV9-Redd1 group displayed increased fluorescence intensity of Redd1 compared with the AAV9-GFP group (Fig. 2A and B). In addition, heart Redd1 protein level was increased nearly three times in the sham operation mice injected with AAV9-Redd1 compared with the sham operation mice injected with AAV9-GFP. Notably, the heart Redd1 protein level was also increased in MI mice injected with AAV9-Redd1 compared with MI mice injected with AAV9-GFP (Fig. 2C and D). In line with preceding studies, the present study discovered that mice undergoing MI surgery exhibited decreased LVEF and LVFS, as well as increased LVEDd and LVESd $(39,40)$, suggesting that MI surgery successfully leads to cardiac insufficiency and ventricular dilatation (Fig. 2E). Parameters of echocardiography in mice at 4 weeks after sham or MI surgery are listed in Table I. Redd1 overexpression significantly increased LVEF and LVFS ( $\mathrm{P}<0.001$; Fig. 2F and G), while LVEDd and LVESd were attenuated (Fig. $2 \mathrm{H}$ and I). Sham+Redd1 group mice displayed no significant changes compared with Sham+GFP group mice. Consistently, the MI+Redd1 group mice also displayed decreased mRNA levels of ANP and BNP compared with the MI+GFP group mice in the border zone (Fig. 2J and $\mathrm{K}$ ). The $\beta$-MHC mRNA level was also slightly decreased after the AAV-Redd1 injection but not significantly (Fig. 2L). Collectively, Redd1 overexpression protected against cardiac dysfunction and cardiac dilatation at 4 weeks after MI after MI. 
A
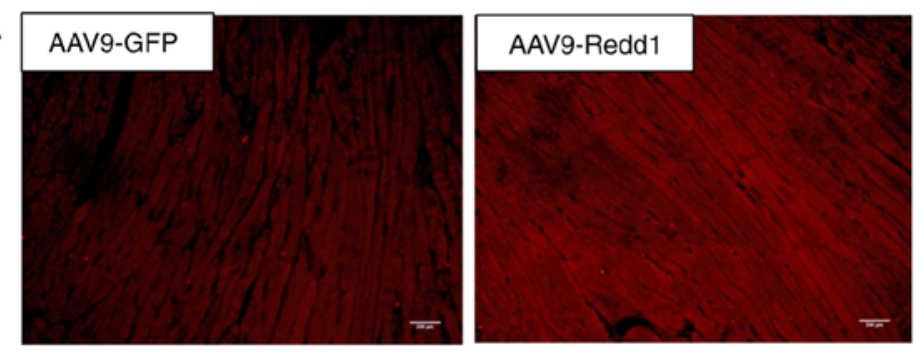

C
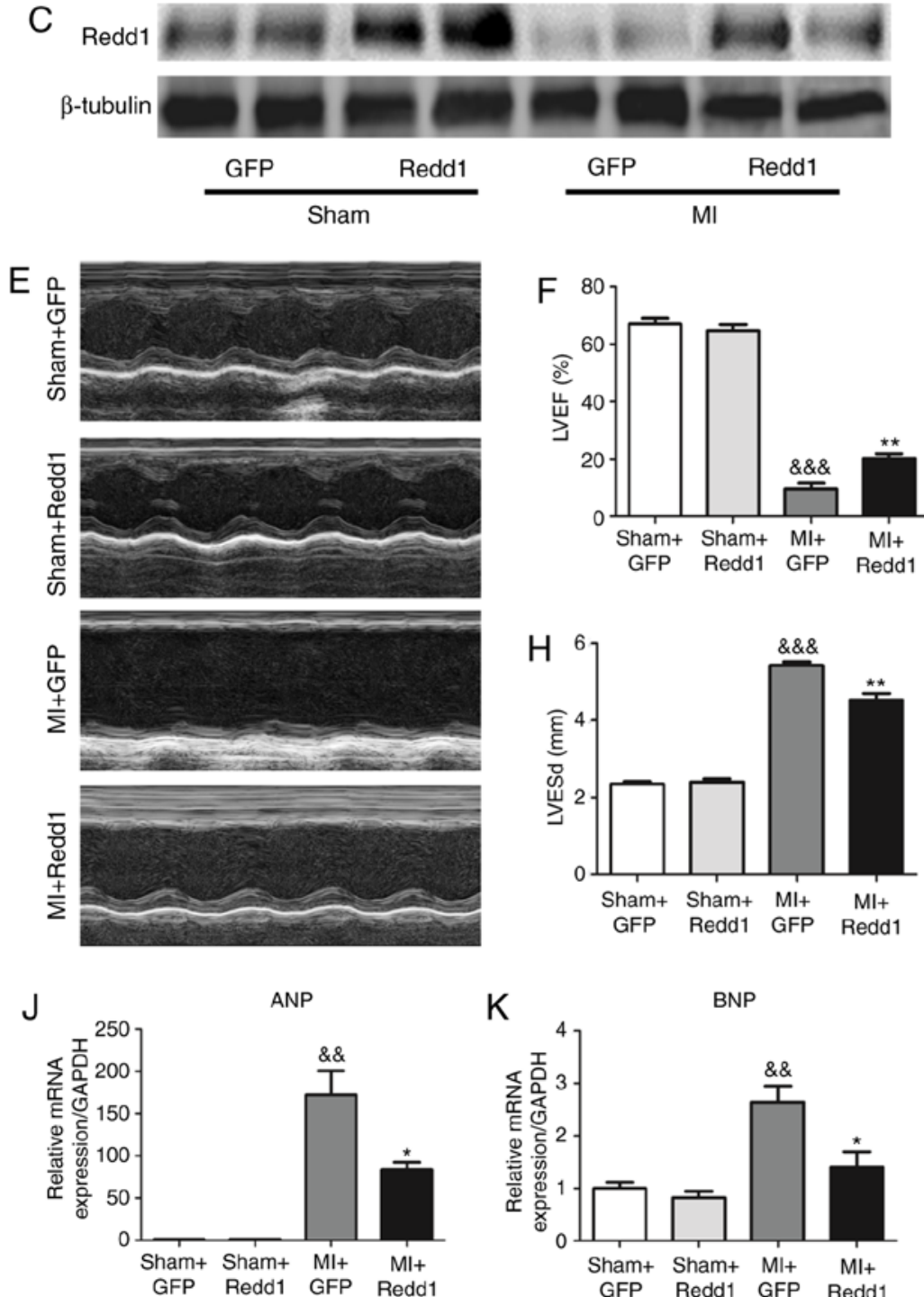

$\mathrm{K}$

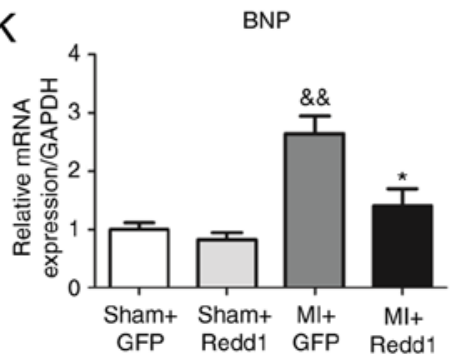

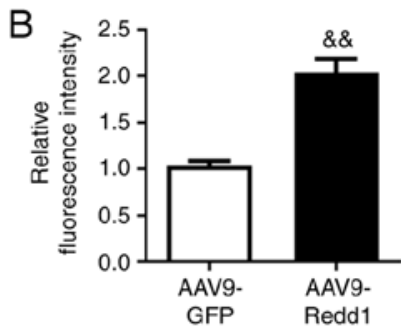
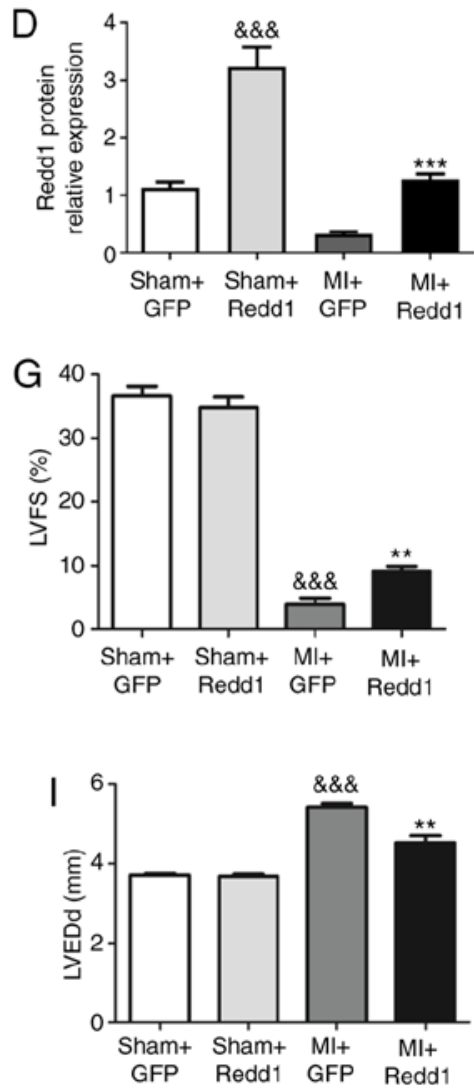

$\mathrm{L}$

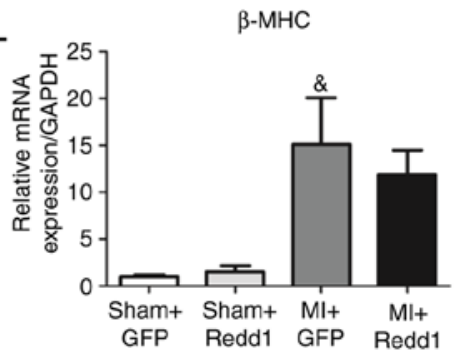

Figure 2. Redd1 overexpression protects against cardiac dysfunction after MI. (A) The temporal expression pattern of Redd1 tested in fluorescence in the heart of AAV9-GFP and AAV9-Redd1 mice. (B) Quantitative results of Redd1 fluorescence intensity (n=6). (C) Protein expression of Redd1 at 4 weeks following MI in the myocardium of mice treated with AAV9-GFP or AAV9-Redd1 and (D) the quantitative analysis (n=6-8). (E) Representative M-mode echocardiography image of the LV from the four groups at 4 weeks after MI. (F-I) Quantitative results of (F) LVEF, (G) LVFS, (H) LVESd and (I) LVEDd of mice from the four groups at 4 weeks after MI $(n=6-8)$. (J) ANP, (K) BNP and (L) $\beta$-MHC determined by reverse transcription-quantitative PCR assay (n=6-8). Data presented as the mean \pm standard error of the mean. ${ }^{\&} \mathrm{P}<0.05$, ${ }^{\&} \mathrm{P}<0.01$ and ${ }^{\&} \& \& \mathrm{P}<0.001$ vs. Sham $+\mathrm{GFP}$ group; ${ }^{*} \mathrm{P}<0.05$, ${ }^{* *} \mathrm{P}<0.01$ and ${ }^{* * * *} \mathrm{P}<0.001$ vs. the $\mathrm{MI}+\mathrm{GFP}$ group. Redd1, regulated in development and DNA damage response-1; MI, myocardial infarction; AAV9, adeno-associated virus 9; GFP, green fluorescent protein; LV, left ventricular; LVEF, left ventricular ejection fraction; LVFS, left ventricular fractional shortening; LVEDd, left ventricular end-diastolic diameter; LVESd, left ventricular end-systolic diameter; ANP, natriuretic peptide type A; BNP, natriuretic peptide type B; $\beta$-MHC, myosin heavy polypeptide 7.

Redd1 overexpression protects against cardiac expansion and fibrosis after MI. To determine cardiac dilatation post MI, heart tissues were stained with Masson's trichrome 4 weeks after MI (Fig. 3A). In the present study, the MI+Redd 1 group displayed a reduced heart expansion index, as well as unaltered scar size and wall thickness compared with the MI+GFP group (Fig. 3B-D). Meanwhile, to analyze cardiac fibrosis, heart tissues were stained with picrosirius red staining in the border zone. The MI+Redd1 group displayed less collagen content compared 
Table I. Parameters in mice at 4 weeks after sham or MI surgery.

\begin{tabular}{lccrr}
\hline Parameters & Sham+GFP $(\mathrm{n}=6)$ & Sham+Redd1 $(\mathrm{n}=6)$ & MI+GFP $(\mathrm{n}=8)$ & MI+Redd1 $(\mathrm{n}=8)$ \\
\hline LVEF (\%) & $67.10 \pm 1.84$ & $64.58 \pm 2.35$ & $9.55 \pm 2.01^{\mathrm{a}}$ & $20.23 \pm 1.59^{\mathrm{b}}$ \\
LVFS (\%) & $36.63 \pm 1.44$ & $34.76 \pm 1.73$ & $4.00 \pm 0.89^{\mathrm{a}}$ & $9.17 \pm 0.76^{\mathrm{b}}$ \\
LVEDd (mm) & $3.71 \pm 0.04$ & $3.68 \pm 0.06$ & $5.54 \pm 0.10^{\mathrm{a}}$ & $4.85 \pm 0.19^{\mathrm{b}}$ \\
LVESd (mm) & $2.35 \pm 0.04$ & $2.40 \pm 0.08$ & $5.42 \pm 0.06^{\mathrm{a}}$ & $4.52 \pm 0.12^{\mathrm{b}}$ \\
\hline
\end{tabular}

Data presented as the mean \pm standard error of the mean. ${ }^{a} \mathrm{P}<0.001 \mathrm{vs}$. Sham $+\mathrm{GFP}$ group; ${ }^{\mathrm{b}} \mathrm{P}<0.01 \mathrm{vs}$. the MI+GFP group. LVEF, left ventricular ejection fraction; LVFS, left ventricular fractional shortening; LVEDd, left ventricular end-diastolic diameter; LVESd, left ventricular end-systolic diameter.
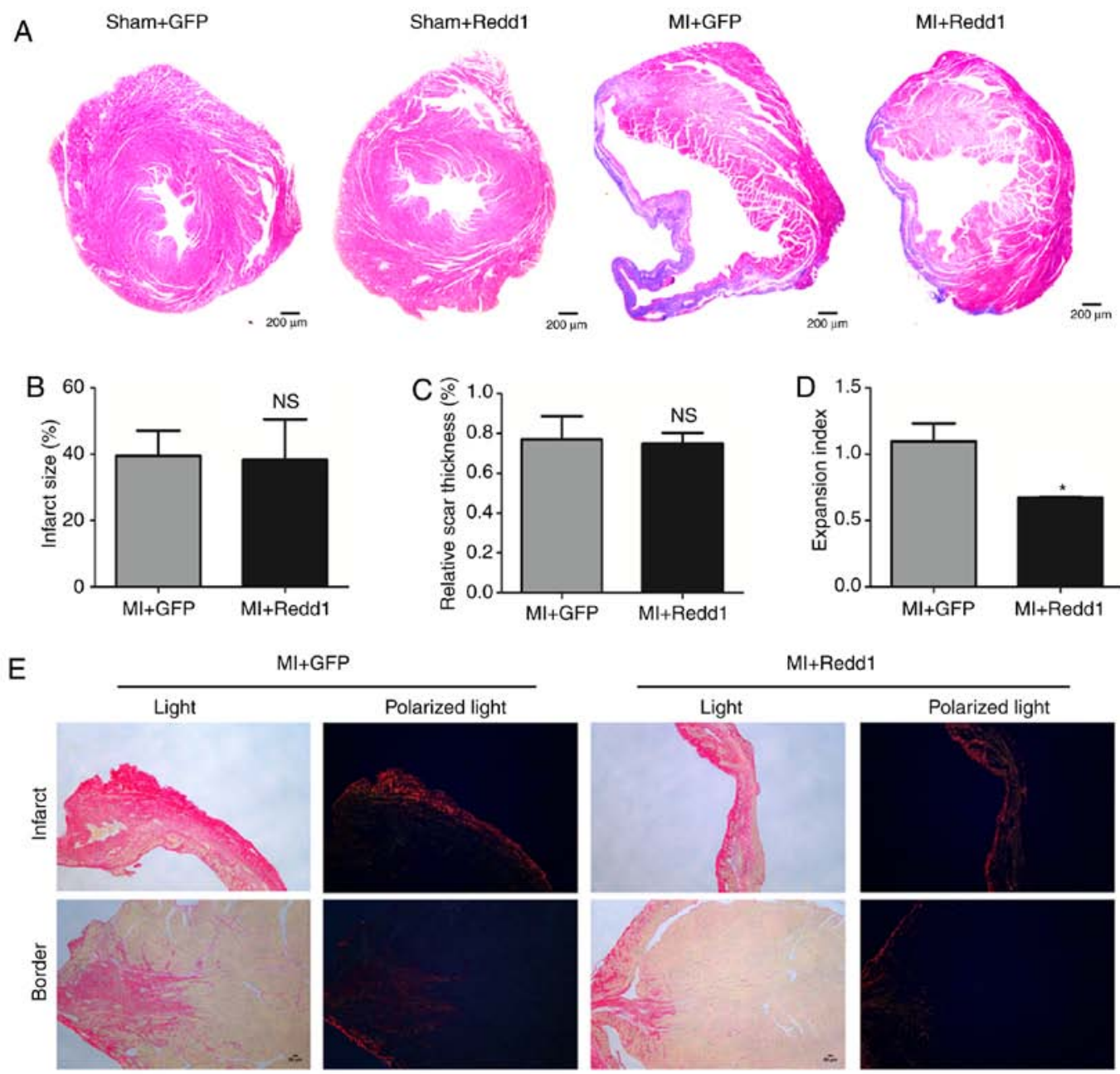

$\mathrm{Ml}+\mathrm{GFP}$
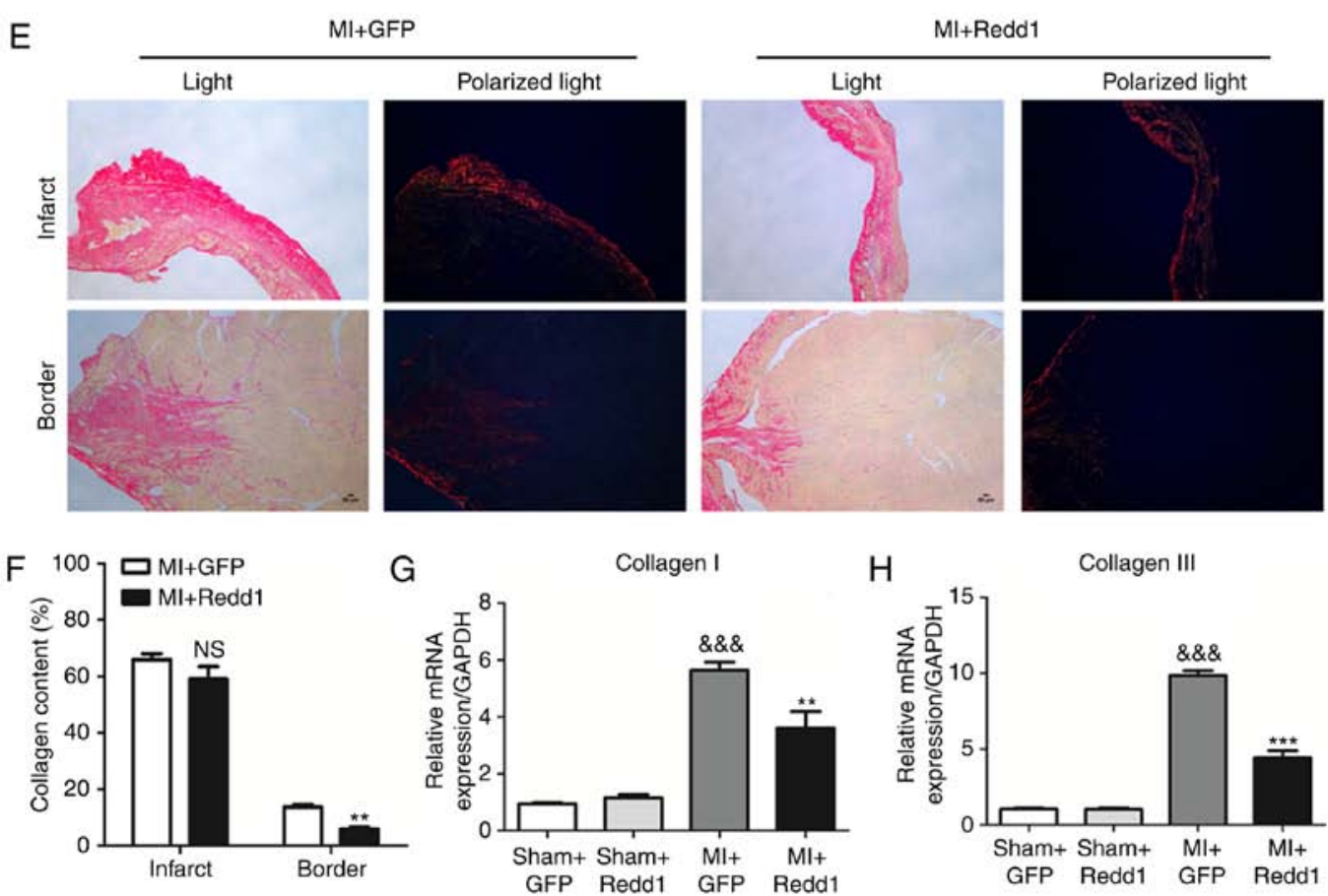

Figure 3. Redd1 overexpression protects against cardiac expansion and fibrosis after MI. (A) Representative Masson's trichrome staining of cardiac sections in the four groups. (B) Quantitative analysis of infarct size, (C) relative scar thickness and (D) expansion index at 4 weeks after MI in MI+GFP and MI+Redd1 mice $(n=6-8)$. (E) Representative picrosirius red-stained sections of infarct and border areas in each group at 4 weeks after MI and (F) the quantitative analysis $(\mathrm{n}=6-8)$. Relative mRNA levels of $(\mathrm{G})$ collagen I and $(\mathrm{H})$ collagen III in the heart of sham-operation mice or in the border zone at 4 weeks post MI surgery $(\mathrm{n}=6-8)$. Data presented as the mean \pm standard error of the mean. ${ }^{\text {\& } \& \&} \mathrm{P}<0.001$ vs. Sham+GFP group; ${ }^{*} \mathrm{P}<0.05,{ }^{* *} \mathrm{P}<0.01$ and ${ }^{* * * *} \mathrm{P}<0.001$ vs. MI+GFP group. NS, not significant; Redd1, regulated in development and DNA damage response-1; MI, myocardial infarction; GFP, green fluorescent protein. 
A
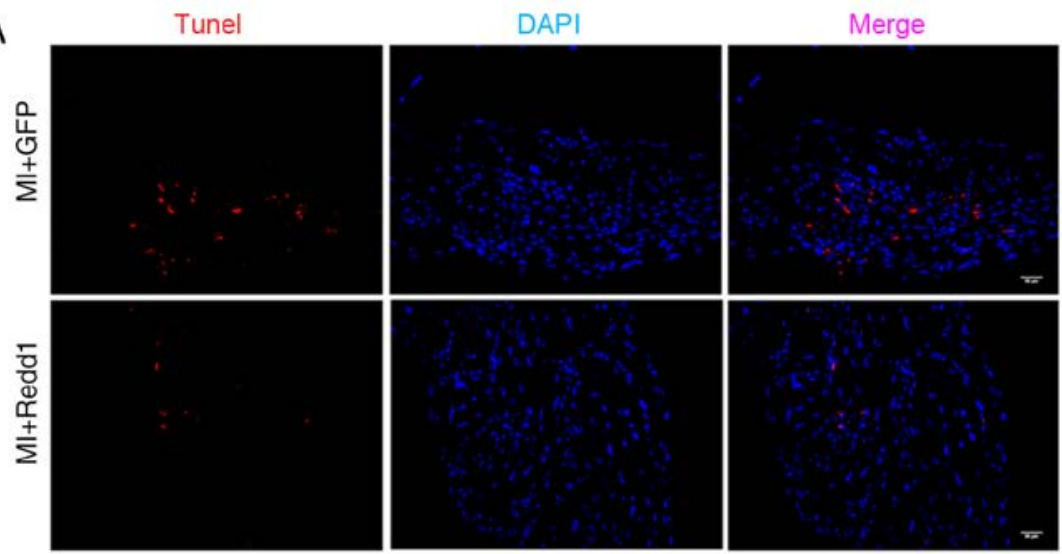

B
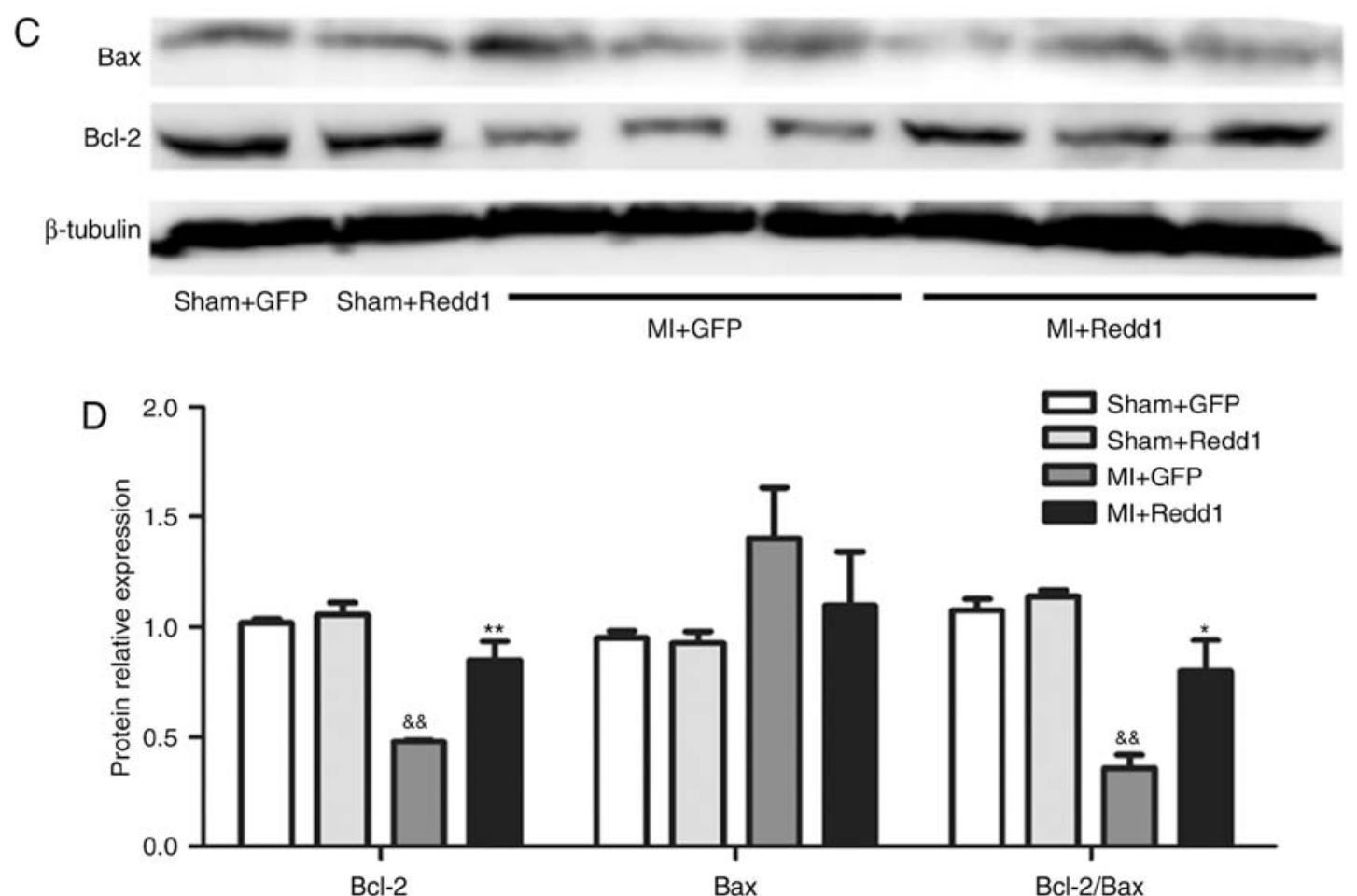

Figure 4. Redd1 overexpression inhibits myocardial apoptosis after MI. (A) Representative images of TUNEL staining showing cardiac cell apoptosis. (B) Quantitative results of TUNEL-positive cells $(\mathrm{n}=6-8)$. (C) Detection of protein levels of Bcl-2 and Bax in each group at 4 weeks after MI. (D) Quantitative results of Bcl-2, Bax and the ratio of Bcl-2/Bax are shown $(n=6-8)$. Data presented as the mean \pm standard error of the mean. \&\&P<0.01 vs. Sham $+\mathrm{GFP}$ group; ${ }^{*} \mathrm{P}<0.05,{ }^{* * *} \mathrm{P}<0.01$ and ${ }^{* * *} \mathrm{P}<0.001$ vs. MI+GFP group. Redd1, regulated in development and DNA damage response-1; MI, myocardial infarction; TUNEL, Terminal deoxynucleotidyl-transferase mediated dUTP nick-end labeling; GFP, green fluorescent protein.

with the MI+GFP group (Fig. 3E and F). Furthermore, MI+Redd1 group mice also exhibited lower mRNA levels of collagen I and collagen III compared with MI+GFP group mice (Fig. 3G and H). Collectively, Redd1 overexpression protected against cardiac expansion and fibrosis after MI.

Reddl overexpression inhibits myocardial apoptosis after MI. In order to explore the effect of Redd1 on cardiac cell apoptosis in the infarct zone, TUNEL staining was conducted. A total of 4 weeks after MI, it was found that the MI+Redd1 group mice displayed decreased TUNEL-positive cells compared with the MI+GFP group (Fig. 4A and B). In addition, the expression of Bcl-2 family members in the infarct zone was examined through western blot assay. The MI+Redd1 group mice exhibited a significant increase in the expression of Bcl-2 and the ratio of Bcl-2/Bax compared with MI+GFP group mice $(\mathrm{P}<0.01$; Fig. $4 \mathrm{C}$ and $\mathrm{D})$. These results showed that Redd1 could attenuate cardiac cell apoptosis in response to ischemia injury.

Reddl overexpression enhances myocardial autophagy after MI. To investigate the effect of Redd1 on myocardial autophagy in the border zone of the infarction, LC3 and Beclin1 levels were measured through western blotting. A total of 4 weeks following LAD ligation, Beclin1 expression and the LC3-II/LC3-I ratio were increased in the MI+Redd1 group mice compared with in the MI+GFP group mice (Fig. 5A-C). Similarly, the ratio of LC3 puncta positive cells to the total cells in the border zone was increased in the MI+Redd1 group mice compared with in the MI+GFP group mice, as well as LC3 puncta per cell (Fig. 5D-F). These results demonstrated 
A

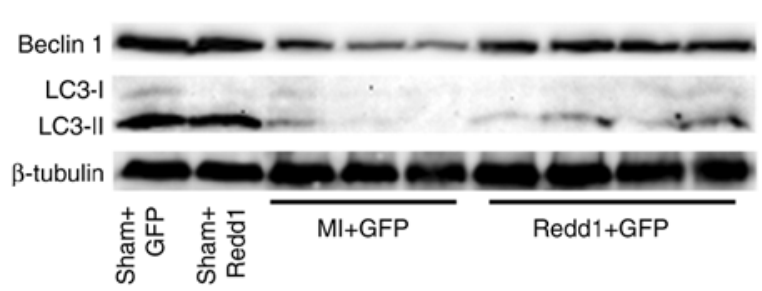

D

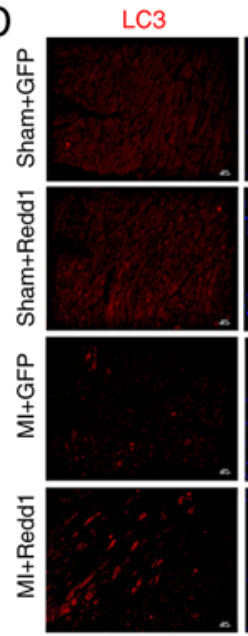

DAPI

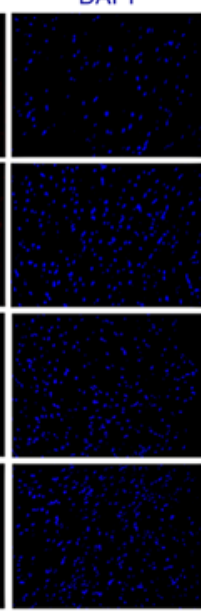

Merge
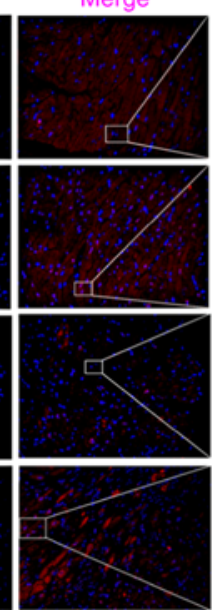

Merge

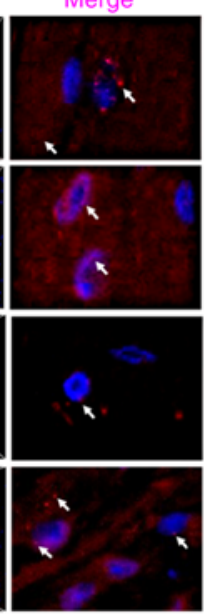

B 2.07 Sham+GFP
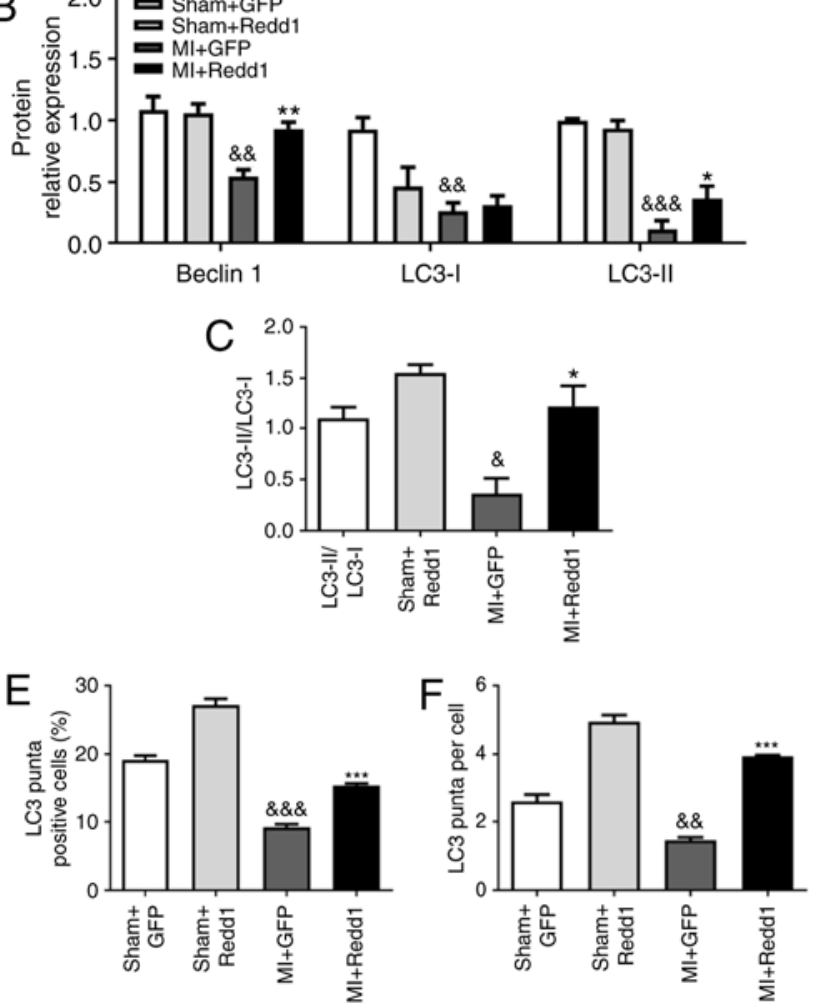

Figure 5. Redd1 overexpression enhances myocardial autophagy after MI. (A) Detection of protein levels of Beclin1 and LC3 in each group at 4 weeks after MI. (B) Quantitative results of Beclin1, LC3-I, LC3-II and (C) the ratio of LC3-II/LC3-I are shown (n=6-8). (D) Detection of autophagosomes by LC3 immunostaining 4 weeks after MI. (E) Quantitative results of LC3 puncta positive cells ( $\mathrm{n}=6-8)$. (F) Quantitative results of LC3 puncta per cell (n=6-8). Data presented as the mean \pm standard error of the mean. ${ }^{\circledR} \mathrm{P}<0.05$, ${ }^{\&}{ }^{\&} \mathrm{P}<0.01$ and ${ }^{\& \&} \& \mathrm{P}<0.001$ vs. Sham+GFP group; ${ }^{*} \mathrm{P}<0.05,{ }^{* * *} \mathrm{P}<0.01$ and ${ }^{* * *} \mathrm{P}<0.001 \mathrm{vs}$. MI+GFP group. Redd1, regulated in development and DNA damage response-1; MI, myocardial infarction; LC3, light chain 3; GFP, green fluorescent protein.

that overexpression of Redd 1 could improve cardiac cell autophagy at 4 weeks after MI.

Redd1 overexpression downregulates the $m T O R / P 70 / S 6$ kinase/4EBPI pathway after MI. To further study whether the mTOR signaling pathway is involved in the regulation of MI mediated by Redd1, the influence of Redd1 overexpression on mTOR phosphorylation level in the border zone of the infarction was measured. MI surgery resulted in increased mTOR phosphorylation, while Redd1 overexpression partially inhibited this effect (Fig. 6A and B). The phosphorylation state of P70/S6 kinase and 4EBP1 was examined and targets of the mTOR1 complex were established. As shown in Fig. 6, Redd1 also significantly decreased the phosphorylation levels of P70/S6 kinase and 4EBP1 ( $\mathrm{P}<0.001$; Fig. 6C and D). These results suggested that Redd1 could alleviate ischemia injury induced ventricular dysfunction partly through the mTOR signaling pathway.

\section{Discussion}

MI is a major cause of morbidity and mortality worldwide $(1,2)$. Although significant progress has been made in minimizing myocardial loss after MI, large numbers of patients still develop heart failure due to myocardial remodeling (41). The present study demonstrated a critical role for Redd 1 in post-MI cardiac dysfunction. The Redd1 expression level decreased in different regions (border area and infarct area) of the infarcted myocardium at 4 weeks. Cardiac-specific overexpression of Redd1 improved cardiac function and decreased cardiac dilatation. This protective effect was produced via inhibiting apoptosis and enhancing autophagy. This pattern indicates that Redd1 plays a protective role in myocardial ischemia injury.

Redd1 has been identified as a critical stress-regulated protein whose expression is transcriptionally induced in various types of cells by DNA damage involved in a variety of physiological and pathological processes (18). Most studies indicate that Redd1 serves an important role in inflammation and autophagy (20-22). In addition, Liu et al (27) explored whether Redd1 attenuated cardiac hypertrophy induced by phenylephrine via enhancing autophagy. Consistent with these results, the present study also demonstrated the protective effect of Redd1 in post-MI cardiac dysfunction. Paradoxically, previous studies have illustrated that inhibition of Redd1 could protect cardiac against I/R injury $(42,43)$. Recently, Gao et al (44) demonstrated that increased Redd1 expression contributed to I/R injury by exaggerating excessive autophagy during reperfusion. The present study supposed that the contradictory conclusion was due to the different models, as Hashmi and Al-Salam (45) has declared that the processes of cardiomyocyte injury in MI and $\mathrm{I} / \mathrm{R}$ were indeed distinct. In addition, the local microenvironment of the myocardium determined the particular roles of molecules and enzymes that were part of their pathogenesis. Actually, the pathological changes, such as inflammation, apoptosis and autophagy in MI vary along with time (46). It makes more sense for further experiments to explore the functions of Redd1 in different periods of MI. 
A

Phospho 4EBP1

Total 4EBP1

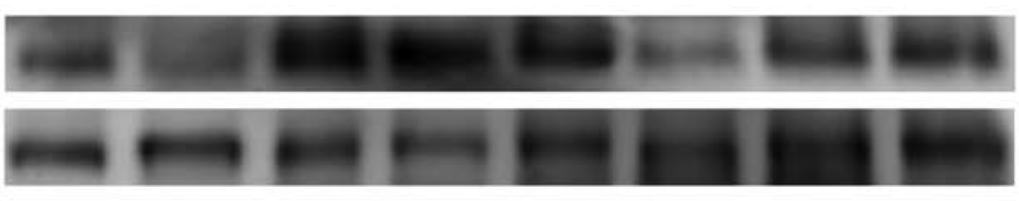

Phospho P70/S6 kinase

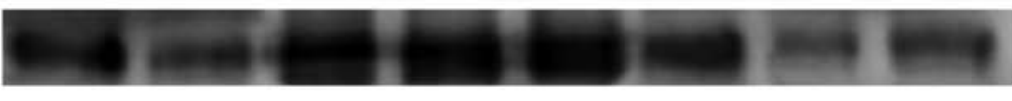

Total P70/S6 kinase
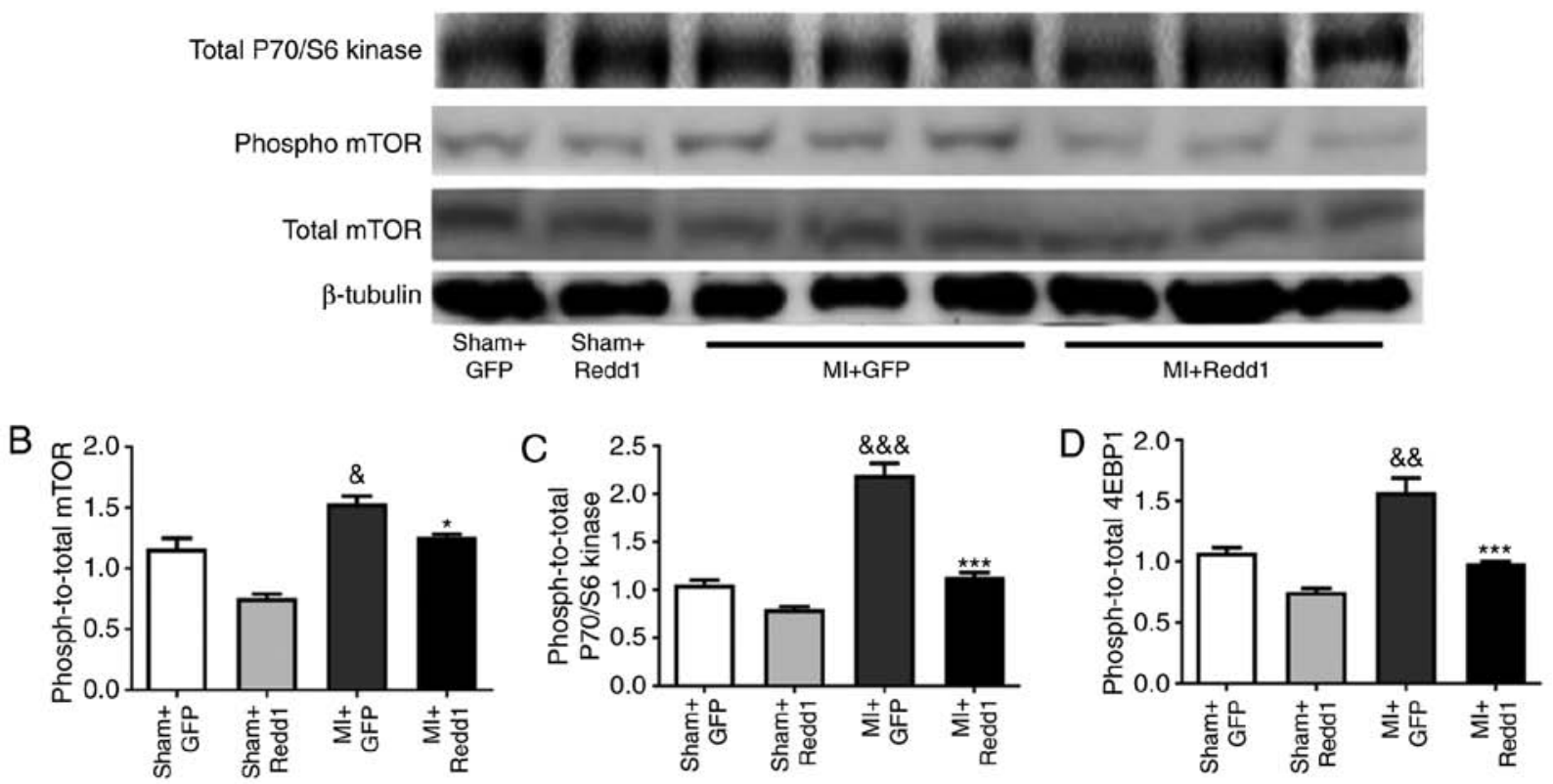

Figure 6. Redd1 overexpression reduces phosphorylation of mTOR after MI. (A) Detection of protein levels of phosphorylation of mTOR and other known downstream molecular targets including P70/S6 kinase and 4EBP1 in the heart of each group at 4 weeks after MI. The phosphorylated-to-total protein ratios of (B) mTOR, (C) P70/S6 kinase and (D) 4EBP1 were quantified ( $\mathrm{n}=6-8)$. Data presented as the mean \pm standard error of the mean. ${ }^{\&} \mathrm{P}<0.05$, ${ }^{\& \&} \mathrm{P}<0.01$ and ${ }^{\& \& \&} \mathrm{P}<0.001$ vs. Sham+GFP group; $\mathrm{P}<0.05$ and ${ }^{* * *} \mathrm{P}<0.001$ vs. MI+GFP group. Redd1, regulated in development and DNA damage response-1; mTOR, mammalian target of rapamycin; MI, myocardial infarction; GFP, green fluorescent protein.

To inspect the underlying mechanism that Redd1 protects against cardiac remodeling and dysfunction, the present study investigated the effect of Redd1 on cardiac fibrosis and apoptosis. The occurrence of cardiac fibrosis has been identified as a definitive characteristic of pathological remodeling and results in cardiac dysfunction post MI (47). Previous research has demonstrated that cardiac fibrosis not only causes systolic dysfunction, but also interrupts the coordination of myocardial excitation-contraction coupling (48). The results of the present study showed that overexpression of Redd1 alleviated heart failure and cardiac fibrosis induced by MI in vivo, as indicated by increased cardiac function and decreased collagen content. Apoptosis, a process of programmed cell death, has been identified in the pathogenesis of myocardial ischemia injury $(7,49)$ and could determine the fate of the heart (50). In the present study, Redd1 overexpression could inhibit myocardial apoptosis in post-MI hearts in vivo. The results indicate that Redd1 can inhibit apoptosis by upregulating the expression of anti-apoptotic molecules Bcl-2 and the ratio of Bcl-2/Bax. However, the exact mechanism underlying Redd1-mediated apoptosis inhibition post MI is not well understood.

Autophagy is a crucial intracellular process which can increase protein turnover and may be involved in preventing the accumulation of aberrant proteins or impaired organelles (51). Autophagy deficiency may be responsible for polyubiquitinated protein accumulation and endoplasmic reticulum stress elevation (52). Autophagy seems to regulate cardiac homeostasis in response to various stresses and has a protective role in the cardiac response to ischemia by removing damaged mitochondria $(8,53)$. A previous study demonstrated that impaired autophagy contributes to adverse cardiac remodeling post MI (54). It has been reported that enhancing autophagy could decrease infarction size and alleviate adverse cardiac remodeling (55), while suppressing autophagy led to adverse cardiac remodeling following MI. The results revealed that autophagy plays a dynamic role in the determination of infarct size and cardiac function. In line with the previous studies, the present study observed that the cardiac cells of MI mice exhibited a lower rate of autophagy $(46,56)$. This was indicated by 2 well-defined markers of Beclin1 (an indicator of autophagy induction) and conversion of LC3-I to lipidated LC3-II (an index of autophagosome abundance), which suggested that impaired autophagy was related to the pathological mechanism of cardiac remodeling in response to MI. However, Redd1 overexpression improved cardiac cell autophagy, accompanied by elevated heart function and reduced cardiac expansion. Based on these results, it can be concluded that Redd1 serves a protective role in enhancing autophagy, therefore ameliorating cardiac remodeling post MI.

mTOR is recognized as a highly conserved serine/threonine kinase that controls cellular metabolism and growth in response to diverse stimuli $(11,57,58)$. Studies have demonstrated that mTOR is necessary for embryonic cardiovascular 
development $(59,60)$. However, selective pharmacological and genetic inhibition of mTOR was shown to reduce myocardial damage after acute and chronic MI (17). Previous studies have demonstrated that mTOR and its downstream signaling pathways can concurrently regulate apoptosis and autophagy (13-15). Furthermore, inhibiting mTOR induced apoptosis and autophagy may exert a protective influence against MI injury $(16,17)$. Consistent with a previous study, the current results revealed that the phosphorylation of mTOR and its downstream signaling pathways were induced in response to MI, along with increased apoptosis and decreased autophagy. Additionally, Redd1 overexpression could inhibit apoptosis and enhance autophagy, as well as suppress the phosphorylation of mTOR. Accordingly, the results of the present study suggest that the inhibition of mTOR signaling pathway contributes to the protective effects of Redd1 on reducing apoptosis and improving autophagy in the myocardium in response to MI surgery. Therefore, the authors speculated that Redd1 protected against cardiac dysfunction and remodeling through inhibiting the mTOR pathway.

In conclusion, the results of the present study have provided the new insight that Redd1 exerts a beneficial influence in improving cardiac dysfunction post-infarction. The cardiac protective effects of Redd1 post MI are associated with the inhibition of apoptosis and the improvement of autophagy. Redd 1 exerts its effect, at least in part, by suppressing the mTOR signaling pathway. However, the precise mechanism by which Redd1 regulates apoptosis and autophagy remains to be elucidated, and further investigations are underway. From the clinical point of view, Redd1 could potentially be a therapeutic candidate for the prevention and treatment of MI-induced irreversible myocardial remodeling and heart failure, reducing the risk of mortality. From a clinical point of view, Redd1 could potentially be a promising therapeutic candidate for patients with MI and other cardiovascular diseases.

\section{Acknowledgements}

Not applicable.

\section{Funding}

The present study was supported by the National Nature Science Foundation of China (grant no. 8157051059), the National Nature Science Foundation of China (grant no. 81601217) and the Natural Science Foundation of Hubei Province (grant no. 2017CFB627).

\section{Availability of data and materials}

The analyzed datasets generated during the study are available from the corresponding author on reasonable request.

\section{Authors' contributions}

PPH designed and performed the study, analyzed the data and wrote the manuscript. JF contributed to conducting the experiments, analyzing data and writing the manuscript. LC, CHJ, KFW and HXL were involved in performing the study. YL and BMQ contributed to data analysis and interpretation. BLQ and
LHL conceived the study, participated in its design and helped to draft the manuscript. All authors read and approved the final manuscript.

\section{Ethics approval and consent to participate}

All experiments were approved by the Ethics committee of Tongji Medical college, Huazhong University of Science and Technology.

\section{Patient consent for publication}

Not applicable.

\section{Competing interests}

The authors declare that they have no competing interests.

\section{References}

1. Michaud CM, Murray CJ and Bloom BR: Burden of disease-implications for fu ture research. JAMA 285: 535-539, 2001.

2. Deedwania PC: The key to unraveling the mystery of mortality in heart failure: An integrated approach. Circulation 107: 1719-1721, 2003.

3. White HD, Norris RM, Brown MA, Brandt PW, Whitlock RM and Wild CJ: Left ventricular end-systolic volume as the major determinant of survival after recovery from myocardial infarction. Circulation 76: 44-51, 1987.

4. Gajarsa JJ and Kloner RA: Left ventricular remodeling in the post-infarction heart: A review of cellular, molecular mechanisms, and therapeutic modalities. Heart Fail Rev 16: 13-21, 2011.

5. Chen J, Hsieh AF, Dharmarajan K, Masoudi FA and Krumholz HM: National trends in heart failure hospitalization after acute myocardial infarction for medicare beneficiaries: 1998-2010. Circulation 128: 2577-2584, 2013.

6. Maejima Y, Kyoi S, Zhai P, Liu T Li H, Ivessa A, Sciarretta S, Del Re DP, Zablocki DK, Hsu CP, et al: Mst1 inhibits autophagy by promoting the interaction between Beclin1 and Bcl-2. Nat Med 19: 1478-1488, 2013.

7. Konstantinidis K, Whelan RS and Kitsis RN: Mechanisms of cell death in heart disease. Arterioscler Thromb Vasc Biol 32: $1552-1562,2012$.

8. Yan L, Sadoshima J, Vatner DE and Vatner SF: Autophagy: A novel protective mechanism in chronic ischemia. Cell Cycle 5: 1175-1177, 2006.

9. Hou L, Guo J, Xu F, Weng X, Yue W and Ge J: Cardiomyocyte dimethylarginine dimethylaminohydrolase1 attenuates left-ventricular remodeling after acute myocardial infarction: Involvement in oxdative stress and apoptosis. Basic Res Cardiol 113: 28, 2018.

10. Liu CY, Zhang YH, Li RB, Zhou LY, An T, Zhang RC, Zhai M, Huang Y, Yan KW, Dong YH, et al: LncRNA CAIF inhibits autophagy and attenuates myocardial infarction by blocking p53-mediated myocardin transcription. Nat Commun 9: 29, 2018.

11. Betz $\mathrm{C}$ and Hall MN: Where is mTOR and what is it doing there? J Cell Biol 203: 563-574, 2013.

12. McMullen JR, Shioi T, Zhang L, Tarnavski O, Sherwood MC, Kang PM and Izumo S: Phosphoinositide 3-kinase(p110alpha) plays a critical role for the induction of physiological, but not pathological, cardiac hypertrophy. Proc Natl Acad Sci USA 100: 12355-12360, 2003.

13. Boluyt MO, Zheng JS, Younes A, Long X, O'Neill L, Silverman H, Lakatta EG and Crow MT: Rapamycin inhibits alpha 1-adrenergic receptor-stimulated cardiac myocyte hypertrophy but not activation of hypertrophy-associated genes. Evidence for involvement of p70 S6 kinase. Circ Res 81: 176-186, 1997.

14. Mazelin L, Panthu B, Nicot AS, Belotti E, Tintignac L, Teixeira G, Zhang Q, Risson V, Baas D, Delaune E, et al: mTOR inactivation in myocardium from infant mice rapidly leads to dilated cardiomyopathy due to translation defects and p53/JNK-mediated apoptosis. J Mol Cell Cardiol 97: 213-225, 2016. 
15. McMullen JR, Sherwood MC, Tarnavski O, Zhang L, Dorfman AL, Shioi T and Izumo S: Inhibition of mTOR signaling with rapamycin regresses established cardiac hypertrophy induced by pressure overload. Circulation 109: 3050-3055, 2004.

16. Yan L, Guo N, Cao Y, Zeng S, Wang J, Lv F, Wang Y and Cao X: miRNA145 inhibits myocardial infarctioninduced apoptosis through autophagy via Akt $3 / \mathrm{mTOR}$ signaling pathway in vitro and in vivo. Int J Mol Med 42: 1537-1547, 2018.

17. Buss SJ, Muenz S, Riffel JH, Malekar P, Hagenmueller M, Weiss CS, Bea F, Bekeredjian R, Schinke-Braun M, Izumo S, et al Beneficial effects of Mammalian target of rapamycin inhibition on left ventricular remodeling after myocardial infarction. J Am Coll Cardiol 54: 2435-2446, 2009.

18. Ellisen LW, Ramsayer KD, Johannessen CM, Yang A, Beppu H, Minda K, Oliner JD, McKeon F and Haber DA: REDD1, developmentally regulated transcriptional target of p63 and p53, links p63 to regulation of reactive oxygen species. Mol Cell 10 995-1005, 2002

19. Tirado-Hurtado I, Fajardo W and Pinto JA: DNA damage inducible transcript 4 Gene: The switch of the metabolism as potential target in cancer. Front Oncol 8: 106, 2018.

20. Brugarolas J, Lei K, Hurley RL, Manning BD, Reiling JH, Hafen E, Witters LA, Ellisen LW and Kaelin WG Jr: Regulation of mTOR function in response to hypoxia by REDD1 and the TSC1/TSC2 tumor suppressor complex. Genes Dev 18 2893-2904, 2004.

21. Lee DK, Kim JH, Kim J, Choi S, Park M, Park W, Kim S, Lee KS, Kim T, Jung J, et al: REDD-1 aggravates endotoxin-induced inflammation via atypical NF- $\mathrm{KB}$ activation. FASEB J 32: 4585-4599, 2018

22. Qiao S, Dennis M, Song X, Vadysirisack DD, Salunke D, Nash Z, Yang Z, Liesa M, Yoshioka J, Matsuzawa S, et al: A REDD1/TXNIP pro-oxidant complex regulates ATG4B activity to control stress-induced autophagy and sustain exercise capacity. Nat Commun 6: 7014, 2015.

23. Canal M, Romani-Aumedes J, Martin-Flores N, PérezFernández V and Malagelada C: RTP801/REDD1: A stress coping regulator that turns into a troublemaker in neurodegenerative disorders. Front Cell Neurosci 8: 313, 2014

24. Ben Sahra I, Regazzetti C, Robert G, Laurent K, Le MarchandBrustel Y, Auberger P, Tanti JF, Giorgetti-Peraldi S and Bost F: Metformin, independent of AMPK, induces mTOR inhibition and cell-cycle arrest through REDD1. Cancer Res 71: 4366-4372, 2011.

25. Hernandez G, Lal H, Fidalgo M, Guerrero A, Zalvide J, Force T and Pombo CM: A novel cardioprotective p38-MAPK/mTOR pathway. Exp Cell Res 317: 2938-2949, 2011.

26. Chen R, Wang B, Chen L, Cai D, Li B, Chen C, Huang E, Liu C, Lin Z, Xie WB and Wang H: DNA damage-inducible transcript 4 (DDIT4) mediates methamphetamine-induced autophagy and apoptosis through mTOR signaling pathway in cardiomyocytes. Toxicol Appl Pharmacol 295: 1-11, 2016.

27. Liu C, Xue R, Wu D, Wu L, Chen C, Tan W, Chen Y and Dong Y: REDD1 attenuates cardiac hypertrophy via enhancing autophagy. Biochem Biophys Res Commun 454: 215-220, 2014.

28. Sciarretta S, Volpe M and Sadoshima J: Mammalian target of rapamycin signaling in cardiac physiology and disease. Circ Res 114: 549-564, 2014

29. Volkers M, Konstandin MH, Doroudgar S, Toko H, Quijada P, Din S, Joyo A, Ornelas L, Samse K, Thuerauf DJ, et al: Mechanistic target of rapamycin complex 2 protects the heart from ischemic damage. Circulation 128: 2132-2144, 2013.

30. Zhao Y, Xiong X, Jia L and Sun Y: Targeting Cullin-RING ligases by MLN4924 induces autophagy via modulating the HIF1-REDD1-TSC1-mTORC1-DEPTOR axis. Cell Death Dis 3 : e386, 2012

31. Prasad KM, Xu Y, Yang Z, Acton ST and French BA: Robust cardiomyocyte-specific gene expression following systemic injection of AAV: In vivo gene delivery follows a poisson distribution. Gene Ther 18: 43-52, 2011.

32. Wang X, Meng H, Chen P, Yang N, Lu X, Wang ZM, Gao W, Zhou N, Zhang M, Xu Z, et al: Beneficial effects of muscone on cardiac remodeling in a mouse model of myocardial infarction. Int J Mol Med 34: 103-111, 2014

33. Oliveira AC, Melo MB, Motta-Santos D, Peluso AA, Souza-Neto F, da Silva RF, Almeida JFQ, Canta G, Reis AM, Goncalves G, et al: Genetic deletion of the alamandine receptor MRGD leads to dilated cardiomyopathy in mice. Am J Physiol Heart Circ Physiol 316: H123-H133, 2019.
34. Jia LX, Qi GM, Liu O, Li TT, Yang M, Cui W, Zhang WM, Qi YF and Du J: Inhibition of platelet activation by clopidogrel prevents hypertension-induced cardiac inflammation and fibrosis. Cardiovasc Drugs Ther 27: 521-530, 2013.

35. Dai W, Hale SL, Martin BJ, Kuang JQ, Dow JS, Wold LE and Kloner RA: Allogeneic mesenchymal stem cell transplantation in postinfarcted rat myocardium: Short- and long-term effects. Circulation 112: 214-223, 2005.

36. Hochman JS and Choo H: Limitation of myocardial infarct expansion by reperfusion independent of myocardial salvage. Circulation 75: 299-306, 1987.

37. Lubbe WF, Peisach M, Pretorius R, Bruyneel KJ and Opie LH: Distribution of myocardial blood flow before and after coronary artery ligation in the baboon. Relation to early ventricular fibrillation. Cardiovasc Res 8: 478-487, 1974.

38. Livak KJ and Schmittgen TD: Analysis of relative gene expression data using real-time quantitative PCR and the 2(-Delta Delta C(T)) method. Methods 25: 402-408, 2001

39. Lee EJ, Park SJ, Kang SK, Kim GH, Kang HJ, Lee SW, Jeon HB and Kim HS: Spherical bullet formation via E-cadherin promotes therapeutic potency of mesenchymal stem cells derived from human umbilical cord blood for myocardial infarction. Mol Ther 20: 1424-1433, 2012.

40. Li Y, Yang R, Guo B, Zhang H and Liu S: Exosomal miR-301 derived from mesenchymal stem cells protects myocardial infarction by inhibiting myocardial autophagy. Biochem Biophys Res Commun 514: 323-328, 2019.

41. Hochman JS, Reynolds HR, Dzavik V, Buller CE, Ruzyllo W, Sadowski ZP, Maggioni AP, Carvalho AC, Rankin JM, White HD, et al: Long-term effects of percutaneous coronary intervention of the totally occluded infarct-related artery in the subacute phase after myocardial infarction. Circulation 124: 2320-2328, 2011

42. Park KM, Teoh JP, Wang Y, Broskova Z, Bayoumi AS, Tang Y, Su H, Weintraub NL and Kim IM: Carvedilol-responsive microRNAs, miR-199a-3p and -214 protect cardiomyocytes from simulated ischemia-reperfusion injury. Am J Physiol Heart Circ Physiol 311: H371-H383, 2016.

43. Zhou Y, Chen Q, Lew KS, Richards AM and Wang P: Discovery of potential therapeutic miRNA targets in cardiac ischemia-reperfusion injury. J Cardiovasc Pharmacol Ther 21: 296-309, 2016.

44. Gao C, Wang R, Li B, Guo Y, Yin T, Xia Y, Zhang F, Lian K, Liu Y, Wang $\mathrm{H}$, et al: TXNIP/Redd1 signalling and excessive autophagy: A novel mechanism of myocardial ischaemia/reperfusion injury in mice. Cardiovasc Res, Jun 26, 2019 (Epub ahead of print).

45. Hashmi S and Al-Salam S: Acute myocardial infarction and myocardial ischemia-reperfusion injury: A comparison. Int $\mathrm{J}$ Clin Exp Pathol 8: 8786-8796, 2015

46. Wang X, Guo Z, Ding Z and Mehta JL: Inflammation, autophagy, and apoptosis after myocardial infarction. J Am Heart Assoc 7: pii: e008024, 2018.

47. Creemers EE and Pinto YM: Molecular mechanisms that control interstitial fibrosis in the pressure-overloaded heart. Cardiovasc Res 89: 265-272, 2011.

48. Berk BC, Fujiwara K and Lehoux S: ECM remodeling in hypertensive heart disease. J Clin Invest 117: 568-575, 2007.

49. Ren J, Zhang S, Kovacs A, Wang Y and Muslin AJ: Role of p38alpha MAPK in cardiac apoptosis and remodeling after myocardial infarction. J Mol Cell Cardiol 38: 617-623, 2005.

50. Krijnen PA, Nijmeijer R, Meijer CJ, Visser CA, Hack CE and Niessen HW: Apoptosis in myocardial ischaemia and infarction. J Clin Pathol 55: 801-811, 2002.

51. Choi AM, Ryter SW and Levine B: Autophagy in human health and disease. N Engl J Med 368: 1845-1846, 2013.

52. Lekli I, Haines DD, Balla G and Tosaki A: Autophagy: An adaptive physiological countermeasure to cellular senescence and ischaemia/reperfusion-associated cardiac arrhythmias. J Cell Mol Med 21: 1058-1072, 2017.

53. Matsui Y, Takagi H, Qu X, Abdellatif M, Sakoda H, Asano T, Levine B and Sadoshima J: Distinct roles of autophagy in the heart during ischemia and reperfusion: Roles of AMP-activated protein kinase and Beclin 1 in mediating autophagy. Circ Res 100: 914-922, 2007.

54. Wu X, He L, Chen F, He X, Cai Y, Zhang G, Yi Q, He M and Luo J: Impaired autophagy contributes to adverse cardiac remodeling in acute myocardial infarction. PLoS One 9: e112891, 2014 
55. Nakai A, Yamaguchi O, Takeda T, Higuchi Y, Hikoso S, Taniike M, Omiya S, Mizote I, Matsumura Y, Asahi M, et al: The role of autophagy in cardiomyocytes in the basal state and in response to hemodynamic stress. Nat Med 13: 619-624, 2007.

56. Wu P, Yuan X, Li F, Zhang J, Zhu W, Wei M, Li J and Wang X: Myocardial upregulation of cathepsin D by ischemic heart disease promotes autophagic flux and protects against cardiac remodeling and heart failure. Circ Heart Fail 10: pii: e004044, 2017.

57. Jewell JL and Guan KL: Nutrient signaling to mTOR and cell growth. Trends Biochem Sci 38: 233-242, 2013.

58. Johnson SC, Rabinovitch PS and Kaeberlein M: MTOR is a key modulator of ageing and age-related disease. Nature 493: $338-345,2013$.
59. Land SC, Scott CL and Walker D: MTOR signalling, embryogenesis and the control of lung development. Semin Cell Dev Biol 36: 68-78, 2014

60. Sciarretta S, Forte M, Frati G and Sadoshima J: New insights into the role of mTOR signaling in the cardiovascular system. Circ Res 122: 489-505, 2018

(i) (2) This work is licensed under a Creative Commons Attribution-NonCommercial-NoDerivatives 4.0 International (CC BY-NC-ND 4.0) License. 